\title{
Идентификация мутаций у больных незавершенным остеогене- зом из Республики Башкортостан
}

\author{
(C) Зарипова А.Р..$^{\star}$, Хусаинова Р.И. ${ }^{1,2}$ \\ ${ }^{1}$ Институт биохимии и генетики УФИЦ РАН, 450054, Уфра \\ ${ }^{2}$ ГБУз Республиканский медико-генетический центр, 450076, Уфра
}

${ }^{\star}$ E-mail: a.ramilna@bk.ru

Проведено молекулярно-генетическое исследование незавершенного остеогенеза в 103 отягощенных семьях. Идентифицированы 9 типов патогененных мутаций у 12 пациентов в генах COL1A1, COL1A2 и IFITM5: 2 дупликации, 1 делеция, 2 нонсенс, 3 миссенс, 1 - сдвига рамки считывания.

Ключевые слова: генетика; наследственные заболевания; незавершенный (несовершенный) остеогенез; гены коллагена; множественные переломы; синдром голубых склер; секвенирование; мутации; полиморфные варианты; NGS-секвенирование.

Незавершенный остеогенез (НО) (МКБ-10: Q78.0, несовершенный остеогенез) - это клинически и генетически гетерогенное наследственное заболевание, характеризующееся многочисленными переломами [1].

Более $80 \%$ случаев НО связаны с доминантно-наследуемыми мутациями в генах COL1A1 или COL1A2 [3]. В остальных случаях, в патогенез заболевания вовлечены 19 «неколлагеновых» генов, многие из которых отвечают за аутосомно-рецессивный тип наследования, за исключением генов IFITM5 и WNT1, которые обусловливают аутосомнодоминантные формы.

В Республике Башкортостан зарегистрирован 151 пациент с НО в 145 семьях, частота заболевания составила 1:27937 населения, что сопоставимо с частотой заболевания в некоторых странах мира.

Учитывая клиническую и генетическую гетерогенность заболевания, а также тяжелое и инвалидизирующее течение, выявление молекулярно-генетической причины каждого конкретного случая НО является актуальной задачей для определения прогноза течения и проведения медико-генетического консультирования отягощенных семей.

Цели и задачи. Целью данного исследования является поиск структурных изменений в генах, участвующих в патогенезе НО, с последующей идентификацией выявленных изменений, определением патогенетической значимости и клинико-генетических корреляций, типа наследования и формы заболевания.

Материалы и методы. В нашей работе были использованы образцы ДНК 116 больных незавершенным остеогенезом из 103 семей и 148 родственников. Основными методами являлись выделение ДНК методом последовательной фенольно-хлороформной экстракции из цельной венозной крови, полимеразная цепная реакция, секвенирование по Сэнгеру и NGS-технология. 
Результаты и обсуждение. В проведенном нами исследовании были идентифицированы 9 типов изменений с патогененной значимостью у 12 пациентов в генах COL1A1, COL1A2 и IFITM5. В гене COL1A1 были идентифицированы следующие патогенные мутации:

- ранее неописанная в литературе мутация с.375dupC, p.Ala126fs, приводящая к сдвигу рамки считывания. У пробанда (пол женский, 1966 г.р.) данная мутация возникла de novo. У пациента обнаружены: тугоухость, голубые склеры, контрактура левого локтевого сустава, тазобедренных и коленных суставов, множественные переломы. У родителей пробанда данная мутация не была найдена. Родители фенотипически здоровы.

- у двух пробандов идентифицирована мутация c.579delT (p.Gly194ValfsX71), в первом случае мутация возникла de novo, во втором - днк отца недоступно для анализа. В литературе мутация описана, как вовлеченная в патогенез НО 1 типа. Это изменение последовательности создает сигнал преждевременной остановки трансляции (p.Gly194Valfs * 71) в гене COL1A1. Варианты с потерей фрункции в COL1A1, как известно, являются патогенными. У первого пробанда (пол мужской, 2002 г.р.), обнаружены следующие клинические проявления: множественные переломы, брахицефалия, синие склеры, гипермобильность суставов, мышечная гипотония, деформация верхних и нижних конечностей, зубы неровные, янтарного цвета, речь с дефектами. У второго (пол мужской, 1995 г.р.), - склеры голубы, рахитические браслетки, гиперподвижность суставов, плоскостопие, сколиоз, дефрормация грудной клетки, множественные переломы [4].

- нонсенс мутация c.967G>T(p.Gly323X) патогенетическая мутация у пробанда (пол женский, 1991 г.р.) и его матери, 1969 г.р.. Данное изменение приводит к НО 1 типа. Клинические проявления заболевания у пациента: у пробанда - 4 перелома, голубые склеры, уши без мочек, зубы светло-коричневые, мышечная гипотония, гиперэксензия суставов, выраженый остеопороз, у матери - около 20 переломов. У отца пробанда данная мутация отсутствует [1].

- нонсенс мутация с.658C>T, p.Arg220* найдена у пробанда (пол мужской, 2012 г.p). Данное изменение приводит к НО 1 типа. Множество переломы, вальгусная деформация конечностей, Голубые склеры, зубы янтарного цвета, крошатся, грудная клетка конической формы. Мать и отец фенотипически здоровы, их ДНК для генетического анализа недоступны [5].

- миссенс мутация c.2461G>A, p.Gly821Ser найдена у пробанда (пол женский, 1992 г.p). Об этом варианте сообщалось у многих людей с несовершенным остеогенезом (HO) типов I-IV, причем HO типа IV является наиболее распространенным (PMID: 26177859, $26627451,27519266,21667357,21884818,17078022)$. Также было показано, что этот вариант возникает de novo у человека, пораженного HO типа III (PMID: 9101304). В анамнезе множественные переломы. Фенотип: сколиоз, деформация нижних конечностей, голубые склеры. Тип наследования на данный момент невозможно выяснить, так как ДНК членов семьи недоступно для анализа $[6,7,8]$.

В гене COL1A2 были идентифицированы следующие патогенетические мутации, являющиеся причиной возникновения НО у пациентов:

- миссенс мутация c.874G>A;p.Gly292Ser у пробанда (пол мужской, 2001 г.p). Согласно базе данных университета Лейдена, мутация описана у пациентов с НО I и III типов. Обнаружено: множественные переломы, плоско-вальгусные стопы, позвоночник искривлен, склеры голубые, зубы желто-янтарного оттенка, выраженная мышечная гипотония, гипермобильность суставов. Тип наследования на данный момент невозможно выяснить, так как ДНК членов семьи недоступно для анализа $[9,10]$. 
- дупликация c.1897_1902dupGCTGGT, p.Ala633_Gly634dup у пробанда (пол женский, 2001 г.р.). Данная мутация не была описана в литературе и по предсказательным программам (in silico) оценена, как вероятно патогенная. Обнаружено: 4 перелома, голова акроцефальной формы, выраженные лобные бугры, голубые склеры, самостоятельно не ходит, множественные деформации верхних и нижних конечностей, килевидная дефрормация грудной клетки, грудной кифоз, низкий рост, саблевидная деформация правого плеча, частичный птоз, гипотиреоз. У матери пробанда данная мутация не найдена, ДНК отца недоступна для генетического анализа.

- миссенс мутация C.G2341C:p.G781R у пробанда (пол мужской, 2016 г.р.), возникшая de novo. В базе данных ClinVar и HGMD описана, как патогенная (CM194715). Данная мутация приводит к НО 1 типа. У пробанда обнаружено: множественные переломы с рождения, крупная голова, склеры голубые.

Также найдена мутация с.-14C>T в гене IFITM5 у трех неродственных пациентов. У двух пациентов наблюдается клиническая картина $\mathrm{V}$ типа $\mathrm{HO}$, у третьего пациента также выявлена ранее неописанная мутация с.1903C>T: p.Arg635* в гене LAMB3, что привело к стертой клинической манифестации V типа НО. Нами впервые было обнаружено сочетание двух молекулярных дефектов у пациентки с основным диагнозом НО V типа [2].

Заключение. Таким образом, нами были идентифицировано: 1 дупликация, 1 делеция, 2 нонсенс и 1 миссенс мутации в гене COL1A1, в гене COL1A2 - 2 миссенс и 1 дупликация. Также найдена мутация -c.-14C>T в гене IFITM5 у трех неродственных пациентов. У одного пациента дополнительно выявлена ранее неописанная мутация С.1903С>Т: p.Arg635* в гене $L A M B 3$, что привело к стертой клинической манифестации.

\section{Литература}

1. Надыршина Д.Д., Хусаинова Р.И., Хуснутдинова Э.К.. Исследование а 1 цепи коллагена 1 типа (COL1A1) у больных несовершенным остеогенезом // Генетика. 2012. Т 48. № 3. C. 372-380.

2. Зарипова А.Р., Нургалиева Л.Р., Тюрин А.В., Минниахметов И.Р., Хусаинова Р.И. Поиск мутаций в гене интерферон индуцированного трансмембранного белка 5

(IFITM5) у больных несовершенным остеогенезом. Медицинская генетика 2019; 18(10): 21-29.

3. Joan C. Marini, An D., Dang Do, Kenneth R Feingold, Bradley Anawalt. Osteogenesis Imperfecta. Endotext [Internet]. South Dartmouth (MA): MDText.com, Inc.; 2000-2020 Jul 26.

4. Zhytnik L., Maasalu K., Pashenko A., etc. COL1A1/2 Pathogenic Variants and Phenotype Characteristics in Ukrainian Osteogenesis Imperfecta Patients. Front Genet. 2019 Aug 9;10:722. doi:10.3389/fgene.2019.00722.

5. Zhang $H_{\text {., }}$ Yang R, Wang Y., etc. A pilot study of gene testing of genetic bone dysplasia using targeted next-generation sequencing. J Hum Genet. 2015 Dec;60(12):769-76. doi: 10.1038/jhg.2015.112.

6. Kloen P, Donders JCE, Eekhoff EMW, Hamdy RC. Pauwels Osteotomy for Femoral Neck Nonunion in Two Adult Siblings with Osteogenesis Imperfecta. Hip Pelvis. 2018;30(1):53-59. doi:10.5371/hp.2018.30.1.53 
7. Mohd Nawawi N, Selveindran NM, Rasat R, et al. Genotype-phenotype correlation among Malaysian patients with osteogenesis imperfecta. Clin Chim Acta. 2018;484:141-147.

doi:10.1016/j.cca.2018.05.048

8. Marini JC, Forlino A, Cabral WA, et al. Consortium for osteogenesis imperfecta mutations in the helical domain of type I collagen: regions rich in lethal mutations align with collagen binding sites for integrins and proteoglycans. Hum Mutat. 2007;28(3):209-221.

doi:10.1002/humu.20429

9. Ho Duy B, Zhytnik L, Maasalu K, et al. Mutation analysis of the COL1A1 and COL1A2 genes in Vietnamese patients with osteogenesis imperfecta. Hum Genomics. 2016;10(1):27. Published 2016 Aug 12. doi:10.1186/s40246-016-0083-1

10. Rolvien T, Stürznickel J, Schmidt FN, et al. Comparison of Bone Microarchitecture Between Adult Osteogenesis Imperfecta and Early-Onset Osteoporosis. Calcif Tissue Int. 2018;103(5):512-521. doi:10.1007/s00223-018-0447-8

The identification of mutations in patients with osteogenesis imperfecta from the Republic of Bashkortostan

Zaripova A.R. ${ }^{1 *}$, Khusainova R.I. ${ }^{1,2}$

${ }^{1}$ Institute of Biochemistry and Genetics Ufa Branch of the Russian Academy of Sciences;

${ }^{2}$ Republican Medical Genetics Center, Ufa; ${ }^{3}$ Bashkir State Medical University, Ufa

*e-mail: a.ramilna@bk.ru

A molecular genetic study of osteogenesis imperfecta in 103 burdened families was carried out. 9 types of pathogenic mutations were identified in 12 patients in the COL1A1, COL1A2 and IFITM5 genes: 2 duplications, 1 deletion, 2 nonsense, 3 missense, 1 frame shift.

Key words: genetics; hereditary diseases; incomplete (imperfect) osteogenesis; collagen genes; multiple fractures; blue sclera syndrome; sequencing; mutations; polymorphic variants; NGS sequencing. 